\title{
Biology, taxonomy and conservation status of the Short-tailed Green Magpie Cissa [t.] thalassina from Java
}

\author{
S. (BAS) VAN BALEN, JAMES A. EATON and FRANK E. RHEINDT
}

\begin{abstract}
Summary
The Short-tailed Green Magpie Cissa thalassina, a member of an Asian lineage of uniquely coloured corvids, is represented by two subspecies, thalassina and jefferyi, that occur on the islands of Java and Borneo, respectively. The distinct Javan nominate form is poorly described in the literature and next to nothing is published on its biology and occurrence in the wild. We here document the biology and distribution of this taxon based on hitherto unpublished historical data and on our own fieldwork. We also analyse vocal data of jefferyi, thalassina and two other Cissa species and show that jefferyi and thalassina are well-differentiated, and that thalassina is bioacoustically more similar to another Cissa species from the Asian mainland. We also demonstrate important and significant biometric differences between jefferyi and thalassina that may reflect divergent adaptations to the environment, as well as plumage differences that may serve signalling functions. Finally, the application of a novel species delimitation test to our data suggests that jefferyi and thalassina deserve to be classified as biological species because their phenotypic divergence exceeds that found in many sympatric species. The revised taxonomic status of Javan thalassina invites a reconsideration of its threat status. Based on its restricted range, extreme rarity and threats by bird trapping and habitat destruction, we consider the Javan Green Magpie as globally Critically Endangered.
\end{abstract}

\section{Introduction}

The Asian genus Cissa Boie, 1826 is a complex of twelve taxa of green magpies. Although sometimes lumped with the five predominantly blue species of Urocissa into one genus (dos Anjos 2009), they form a discrete lineage, members of which look uniform with a green plumage, unique amongst corvids. Their present taxonomic relationships are still insufficiently studied, and in particular the taxonomic status of both races of Short-tailed Green Magpie Cissa thalassina needs to be elucidated (Wolters 1977, Dickinson et al. 2004).

To date the following taxa have been described: (I) chinensis - Himalayas and northern Indochina, (2) minor - Sumatra and Borneo, (3) robinsoni - extreme south-west Thailand and peninsular Malaysia, (4) klossi - central Annam (Vietnam) and central Laos, (5) margaritae - Mt Lang Bian (central-southern Vietnam), (6) hypoleuca - south-east Thailand, central and southern Laos, southern Vietnam (southern Annam and Cochinchina), (7) chauleti - central Annam (Vietnam), (8) concolor - eastern Tonkin and northern Annam (north Vietnam), (9) jini - southcentral China, (10) katsumatae - Hainan Island, (II) thalassina - west and central Java, (12) jefferyi - northern Borneo.

Various arrangements have been described on geographical and morphological grounds. The most speciose was by Delacour (1929) who recognised six species: C. chinensis (taxa 1-5), C. hypoleuca (taxa 6-7), C. jefferyi, C. katsumatae, C. concolor (taxa 8-9) and C. thalassina. 
Kuroda (1933) and Chasen (1935) lumped all forms into one species. Vaurie (in Peters 1962) recognised two species: Green $C$. chinensis (taxa 1-5) and Short-tailed Magpie C. thalassina (taxa 6-12). This system was followed by Sibley and Monroe (1990), who, however, considered the latter as having three distinct subspecies: Yellow-breasted, Bornean and Short-tailed Magpie. Goodwin $(1976,1986)$ grouped the forms into three species: Common C. chinensis (taxa 1-5), Indochinese C. hypoleuca (taxa 6-10) and Short-tailed C. thalassina (taxa 11-12), and this is followed by many subsequent standard works, such as Walters (1980) and Howard and Moore (1980). These three species are considered a superspecies by dos Anjos (2009), an arrangement that is obviously mistaken in view of the sympatry between Common Green Magpie and both other species.

The (sub)specific distinctions are based on body size, tail length and shape, colour pattern of tertials and tail, and yellow wash on body and crown (see Table 1). Both Short-tailed Magpie taxa (thalassina and jefferyi) are mainly distinguished by their short tails. Not surprisingly, vocalisation has never been used as a taxonomic character as this aspect of the genus is complex, and rather intangible as in most corvids, due to intergradation, individual variation, frequent vocal mimicry, etc. (dos Anjos 2009). Cissa thalassina was first described by Temminck in 1826 . Although being lumped with the other green magpies, the race thalassina is described as a very distinct form by Kuroda (1933). In this paper we use morphological characters as well as vocal characters to examine the level of differentiation between jefferyi and thalassina. We also use a novel phenotypic species delimitation test (Tobias et al. 2010) to evaluate if phenotypic differences between jefferyi and thalassina are comparable to other pairs of sister taxa that are ranked at the biological species level.

Very little is published on the natural history of the distinct Javan race of Short-tailed Green Magpie (Madge and Burn 1994, dos Anjos 2009), and its specific name thalassina (meaning sea-green or bluish-green, the general colour of preserved skins or of birds kept in captivity) given by its describer, C. J. Temminck in 1826, is symptomatic of the status of knowledge of these birds in their natural environment, described as rugged and inaccessible (de Visard de Bocarmé 1829).

This paper summarises all that is presently known about the biology and status of the Javan Short-tailed Green Magpie. Once listed as near-threatened in Collar et al. (1994), Short-tailed Green Magpie was not considered in BirdLife International (2001). New insight into its taxonomy necessitates a reassessment of its global status.

Table 1. Measurements and plumage characteristics for three Cissa taxa (from Madge and Burn 1994).

\begin{tabular}{|c|c|c|c|}
\hline & thalassinaljefferyi & hypoleuca & chinensis \\
\hline Tail length (mm) & $97-110$ & {$[114-] 157$} & $171-210$ \\
\hline Body length $(\mathrm{cm})$ & $31-33$ & $34-35$ & $37-39$ \\
\hline Tail shape & $\begin{array}{l}\text { short, bluntly } \\
\text { graduated }\end{array}$ & $\begin{array}{l}\text { intermediate, } \\
\text { central feathers hardly } \\
\text { project beyond next pair }\end{array}$ & strongly graduated \\
\hline Tertials & $\begin{array}{c}\text { no obvious } \\
\text { pattern }\end{array}$ & $\begin{array}{l}\text { Plain, broadly tipped \& } \\
\text { fringed green, no spotting }\end{array}$ & $\begin{array}{l}\text { tipped with black- } \\
\text { and-white spots }\end{array}$ \\
\hline Underparts & green & $\begin{array}{l}\text { strongly washed lemon- } \\
\text { yellow }\end{array}$ & pea or leaf green \\
\hline Crown colour & green & green & $\begin{array}{c}\text { yellowish green (most races) } \\
\text { to bright golden yellow }\end{array}$ \\
\hline Crown structure & shorter feathers & intermediate? & $\begin{array}{l}\text { elongated rear crown \& } \\
\text { nape feathers }\end{array}$ \\
\hline
\end{tabular}




\section{Material and methods}

\section{Data acquisition}

We gathered sound recordings for both currently recognised subspecies of $C$. thalassina as well as for a number of individuals each of $C$. chinensis and $C$. hypoleuca. Recordings of different subspecies of $C$. hypoleuca and $C$. chinensis were each pooled for vocal analysis. We recorded vocalisations in the field in Indonesia, Cambodia and Vietnam and supplemented our own recordings with those made by colleagues and deposited in the xeno-canto ornithological sound collection (www.xeno-canto.org). Details of all 18 recordings, including localities, dates and names of the sound recordists, can be found in Table $\mathrm{S}_{1}$ in the online Supplementary Materials.

Two major collections, National Museum of Natural History (Nederlands Centrum voor Biodiversiteit (NCB) Naturalis, Leiden, Netherlands) and the Natural History Museum (Tring, UK) provided the skins that were examined for a mensural analysis. In the analyses, 21 skins of Cissa t. thalassina and 1o Cissa t. jefferyi were measured, with near-equal numbers (I:I) for males and females for each taxon (Table S2).

Field observations were made during general and more specialised forest bird surveys on Java between 1980 and 1997 (S. v. B), and excursions in 2002-2010 (J. A. E). Data on museum specimens, publications in often obscure journals, and birding reports provided historical data on distribution and biological information. Requests for field data yielded a small additional number of field observations.

\section{Bioacoustic analysis}

Both analogue and digital recordings were converted into WAV format if they had not been initially created in that format. Recordists used different equipment for sound recordings. However, we consider any bias caused by equipment differences on parameter measurements to be negligible. For instance, the level of variability in background noise and slight differences in note shape among recordings from the same recordist are equivalent to the variability among recordings from different recordists, indicating that differences in recording quality are much more important than equipment differences. Furthermore, in many cases we analysed multiple recordings from several different recordists for each taxon, which should remove any such bias. In each case, we made an attempt to account for levels of sound pollution in our measurements by setting the background level equal.

We prepared and analysed sonograms of vocalisations using the program Syrinx version $2.6 \mathrm{~h}$ by John Burt (available at www.syrinxpc.com). Levels of background noise were set to an equal level, otherwise default settings were employed. Cissa vocalisations are characterised by great variability and a large individual repertoire of notes and song motifs. In order to carry out meaningful comparisons among taxa, we classified sounds in each recording into one of twelve different motif types, each designated by a unique letter ranging from A to L. Each motif type consists of one to several notes. For each motif type in each recording, we then counted the number of times the motif was uttered, as well as the number of notes the motif contained. We compared overlap in the presence of motif types among taxa as well as overlap in the number of notes per motif type in each taxon.

Since many motif types in Cissa, especially the non-melodious ones, are characterised by harmonics (component frequencies of waves that are an integer multiple of the fundamental frequency), we also noted their presence or absence in the motifs of each recording and used a binomial test to compare taxon-specific incidence of harmonics. In poor recordings, harmonics can be difficult to detect even when present. However, virtually all our recordings were loud enough for harmonics to show up on the sonogram in the presence of several multiples, and multiple recordings were sampled for each taxon so we rule out recording quality as a confounding factor in comparisons of harmonics. We measured three different frequency parameters (highest frequency, lowest frequency and frequency range) as well as the duration for each motif and compared them among all taxa. 
One set of comparisons involved an across-taxon Kruskal-Wallis test and pairwise two-tailed Mann-Whitney U-tests of the frequency parameters (not the duration) of all motifs measured for each taxon, regardless of motif type, to test for taxon differences in general vocal pitch. In another set of inter-taxon comparisons, we contrasted frequency parameters and duration of shared motifs among taxa to check for overlap in measurements. Since only six motifs were shared amongst 2-3 taxa, and there were only 1-6 sample recordings per taxon per shared motif, sample size for this second set of comparisons was too low for statistical analysis and overlap was only evaluated in comparisons involving more than one sample recording in at least one taxon. All statistical analysis was carried out using the program SPSS (SPSS Institute Inc., Chicago).

\section{Biometric analysis}

We measured eight biometric traits for 21 individuals of thalassina and to individuals of jefferyi (each 50\% male and 50\% female): tail length, wing length, bill height, bill length, total length, tarsus, tail/wing ratio and tarsus/wing ratio. Table 4 lists all measurements and specimen details including museum voucher numbers. Female and male specimens were pooled for each species, because sample sizes for significance testing of sex-specific groups were too low, and because we did not detect any sexual dimorphism. For each trait, we performed a two-tailed Mann-Whitney U-test to examine differences between the two taxa. To increase the stringency of this test, we considered a difference significant at $P \leq$ o.o1. Once significant differences were detected between the two taxa, we additionally examined if the measurements for a particular trait passed a second - more stringent significance hurdle by assessing if the ranges of measurements for either taxon overlapped.

\section{Phenotypic species delimitation test}

We used the species delimitation criteria recently proposed by Tobias et al. (2010) to assess the biological species status of thalassina and jefferyi based on the biometric, ecological, behavioural, and plumage characters presented in this paper. This species delimitation test assesses phenotypic differences between two taxa by assigning each character difference a score of $1-4$, based on whether the difference can be considered 'minor', 'medium', 'major' or 'exceptional'. The final score of a comparison is then applied against a threshold generated from a large global sample of sympatric bird species; if it exceeds the threshold, phenotypic evidence can be seen to support species status. For exact definitions of categories and assignment rules, see Tobias et al. (2010).

\section{Results}

\section{Bioacoustics}

For the Bornean jefferyi the call is described as "not nearly so clear as that of C. minor, but is still a feeble attempt at 'Ton-ka-kis'" (Whitehead 1893: 206). Interestingly, the main calls of the Javan taxon thalassina appear to show a greater resemblance to the hypoleuca and chinensis complexes, than to its present congener jefferyi. On Java, the Sundanese names èkèk gêling, kèkèt gêlèng, dèrètdèt kêlèng, kèrèkèk kêlèng, cucak keling (WJ), and Javanese names dingdingbak (CJ), and kekek kelang (Yogya) and variations (Bartels 1897-1931, Koningsberger 1907, van Oort 1910, S. v. B. unpubl. data) closely describe the most stereotypic call of its large repertoire, which also includes mimicking, and is accurately described as "a nasal chiuu - chiuu - kèkèng ê ngliéng", also "uttered in flight" (Bartels 1897-1931, J. H. Becking unpubl. data).

Vocal parameters for each taxon are specified in Table $S_{I}$ in the online Supplementary Materials. In our 18 recordings of four taxa, we found 12 different motif types (A-L), six of which (A-F) were shared amongst more than one taxon. Fig. I depicts a typical example of each motif type, and Fig. 2 shows the overlap in motif types among taxa, indicating that $C$. t. thalassina and 
A

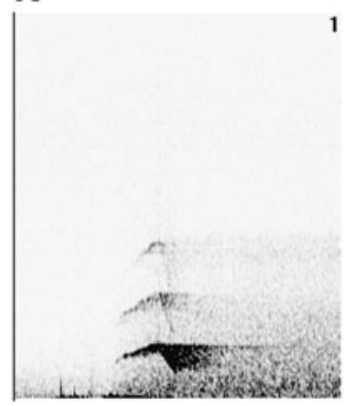

D

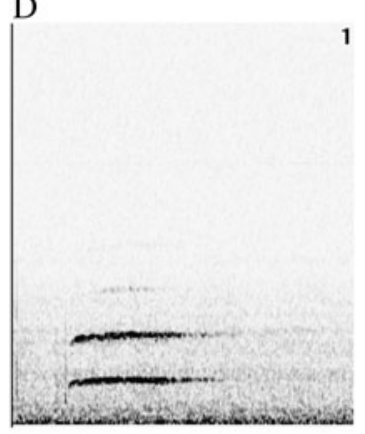

G
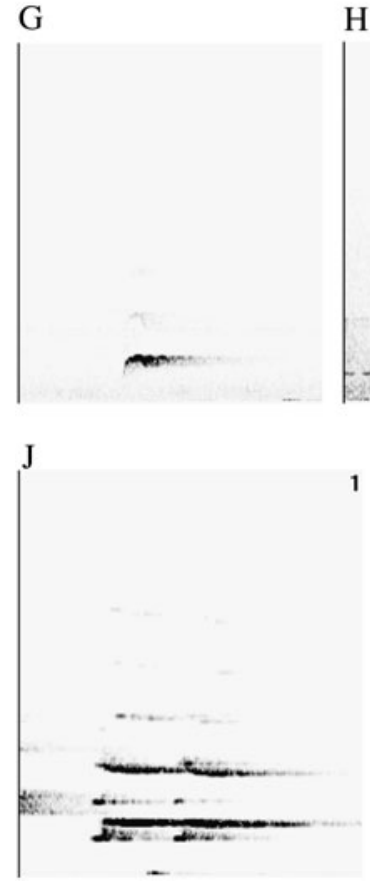

B

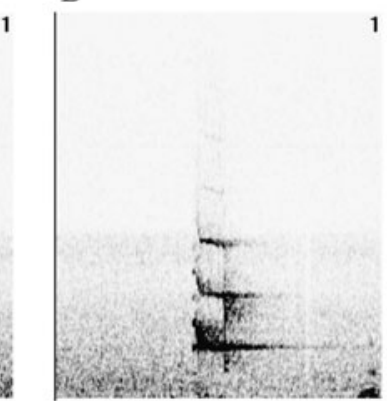

E
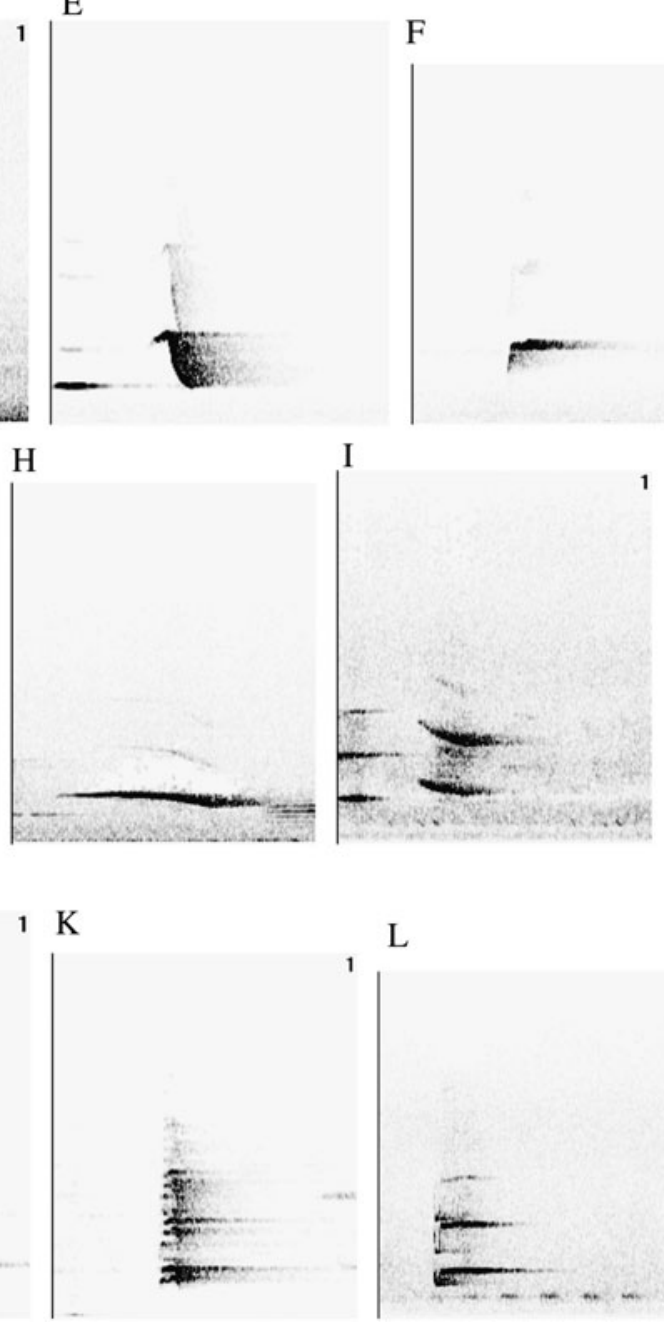

C

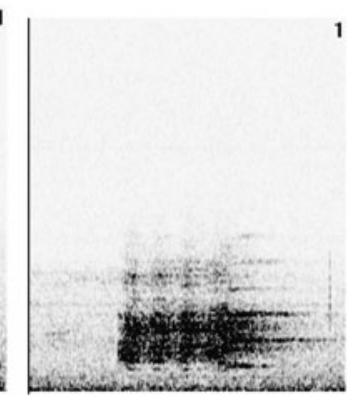

$\mathrm{F}$

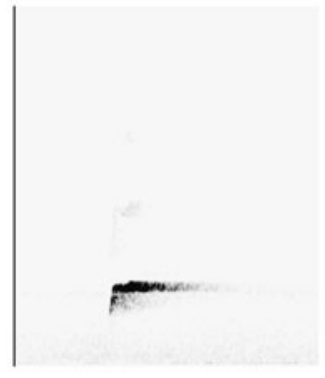

$\mathrm{L}$

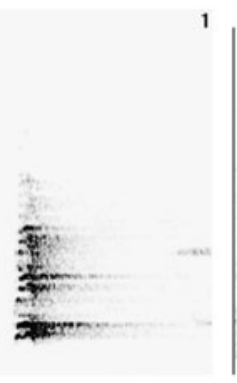

1

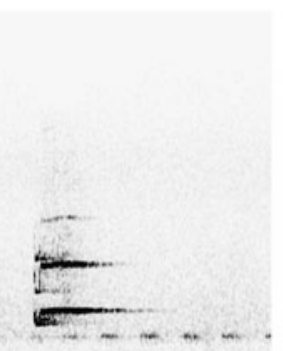

Figure 1. Twelve motifs found in Cissa vocalisations. 
C. t. jefferyi only share a single motif type (D) that is also present in C. hypoleuca. On the other hand, overlap between C. t. thalassina and C. hypoleuca is particularly pronounced, with four shared motif types, three of which are exclusive to these two taxa.

In our assessment of whether the number of notes given by each taxon for each shared motif type (i.e. motifs A-F) is approximately equal, we found that there is complete overlap in the number of notes given by each taxon for motifs A, B, D, E and F. The only shared motif that showed no overlap is $\mathrm{C}$, which is characterised by 3-4 notes in C. t. thalassina and two notes in C. hypoleuca. However, an increased sample size could easily establish overlap for the number of notes given for motif $\mathrm{C}$ by these two species. All in all, we interpret the lack of inter-taxon differences in the number of notes given for each motif type to corroborate that our definition of shared motif types is robust and that only homologous vocalisations were grouped into common motif types.

Each vocalisation was scored for the presence or absence of harmonics, and a binomial test showed that there is a significant propensity for $C$. t. jefferyi to lack harmonics in its vocalisations (two-tailed $P$-value < O.001). No such propensity was found in the other taxa, although $C$. hypoleuca exhibited a near-significant propensity for uttering vocalisations containing harmonics (two-tailed $P$-value $=0.09$ ), which - with increased sampling - may well turn out to be a real vocal characteristic that sets this taxon apart.

We compared three frequency parameters in the overall vocal repertoire amongst each taxon, regardless of motif type. A Kruskall-Wallis test $(P=0.418)$ and pairwise Mann-Whitney U-tests (results not shown) yielded no significant differences among taxa in the highest vocal frequencies of motif delivery. Equally, taxa did not differ significantly in terms of the frequency range of overall motifs uttered (Kruskal- Wallis: $P=0.314$; pairwise Mann-Whitney U-test: not shown). The only frequency differences detected refer to the lowest frequencies (Kruskal-Wallis: $P=0.075$ ) of overall motif delivery in C. t. thalassina, which were significantly lower than in C. t. jefferyi (two-tailed Mann-Whitney U-test: $P=0.016$ ), and almost significantly lower than in $C$. hypoleuca $(P=0.079)$ and $C$. chinensis $(P=0.12)$. In contrast, no differences in lowest

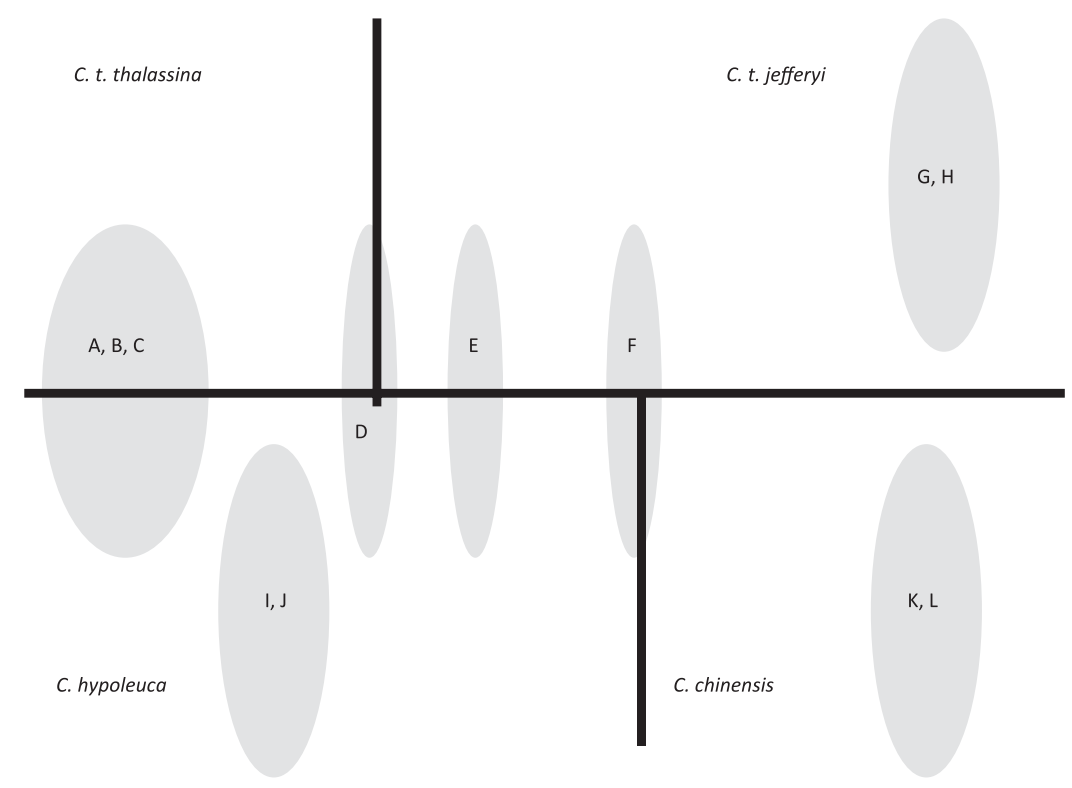

Figure 2. Motif types unique to each taxon or shared among taxa; letters refer to motif types as shown in Fig. 1 . 
frequencies were found in comparisons involving C. t. jefferyi, C. hypoleuca and C. chinensis, but to the exclusion of C. t. thalassina.

As only six (A-F) out of twelve motif types were shared among a range of $2-3$ taxa, and since motifs were represented only $1-6$ times in each taxon (Table 2), sample size for motif-specific vocal comparisons was too low for statistical analysis. Nonetheless, we performed a crude comparison among taxa using all three frequency parameters and motif duration to check for general overlap in these measurements. Wherever a shared motif was represented by more than one measurement in at least one taxon in our sampling regime (i.e. in motifs A, B, D, E and F; Table 2), we ascertained whether the value(s) for the other $1-2$ taxa overlapped with this range. We found a complete overlap of measurements for motifs $\mathrm{D}$ and $\mathrm{E}$ in all three frequency parameters and in motif duration (Table 2). For motifs A and B, there was measurement overlap between the two taxa involved (C. t. thalassina and C. hypoleuca) only at the highest frequency, but not in the other three vocal parameters (Table 2). Similarly, in motif $F$, there was overlap among C. t. jefferyi, C. hypoleuca and C. chinensis only at the lowest frequency, but not in the three remaining parameters. It is important to note that a higher sample size may lead to the detection of fine-scale vocal differences between taxa in overlapping parameters or - conversely - may show vocal overlap in parameters that seem to differ among taxa using the current dataset. Overall, we expect many motifs to share the same vocal properties among taxa, and we interpret this result as confirmation that we have generally classified homologous vocalisations into equal motif categories. Even in homologous vocalisations that are appropriate for comparative analysis, taxon-specific differences in some vocal parameters are expected to involve at least a number of motif types, so differences in motifs A, B and F may well be real indicators of vocal differentiation between Cissa taxa.

\section{Morphology}

\section{Biometrics}

Table 3 shows the measurements of eight biometric parameters of 21 specimens of thalassina and 1o jefferyi. Table 4 gives the mean values and $P$-values using a two-tailed Mann-Whitney U-test. Bornean jefferyi has a significantly shorter wing length than thalassina (although their measurements display some overlap), and a comparatively even shorter tarsus length with no overlap in measurements. Accordingly, the tarsus-wing ratio showed significant differences although measurements overlapped. In terms of tail length, size dimensions are reversed, as jefferyi displays significantly longer measurements than thalassina, with no apparent overlap, and intermediate between thalassina and the other species of green magpie (Tables 1 and 3 ). Consequently, tail-wing ratios also differ significantly between both taxa, with no overlap in measurements. Whilst bill length does not differ significantly between the two taxa, bill heights are significantly different between the two species with no overlap in measurements, resulting in

Table 2. Biometrics of two taxa of Short-tailed Green Magpie (all measurements in mm, unless indicated otherwise; from skins stored in the Leiden Museum, mostly thalassina, and Tring, mostly jefferyi). Mann-Whitney U-test $P$-values are given.

\begin{tabular}{|c|c|c|c|c|c|c|c|c|c|}
\hline & & Wing L & Tail L & Bill L & Bill H & Tarsus & $\begin{array}{l}\text { Total L } \\
(\mathrm{cm})\end{array}$ & $\begin{array}{l}\text { Tarsus/ } \\
\text { wing }\end{array}$ & $\begin{array}{l}\text { Tail/ } \\
\text { wing }\end{array}$ \\
\hline \multirow{3}{*}{$\begin{array}{l}\text { thalassina } \\
\qquad(n=21)\end{array}$} & mean & 137.2 & 107.2 & 35.9 & 15.4 & 42.3 & 26.3 & 0.31 & 0.78 \\
\hline & SD & 3.0 & 4.8 & 2.1 & 0.8 & 1.4 & 1.5 & 0.01 & 0.04 \\
\hline & range & $133-142$ & $101-118$ & $32.5-41.0$ & $13.9-17.0$ & $40.1-45.0$ & $24 \cdot 5-30$ & $0.29-0.33$ & $0.75-0.87$ \\
\hline \multirow{3}{*}{$\begin{array}{l}\text { jefferyi } \\
\qquad(n=10)\end{array}$} & mean & 132.8 & 124.9 & $34 \cdot 3$ & 12.7 & 39.4 & $27 \cdot 4$ & 0.30 & 0.94 \\
\hline & SD & 2.1 & 4.1 & 1.6 & 0.8 & 1.3 & 0.5 & 0.02 & 0.02 \\
\hline & range & $130-136$ & $118-129$ & $32.2-36.7$ & $11.0-13.6$ & $37 \cdot 7-42 \cdot 3$ & $27-28$ & $0.29-0.32$ & $0.90-0.97$ \\
\hline$P$ & & 0.0006 & $<0.0001$ & 0.0404 & $<0.0001$ & 0.0001 & 0.0193 & 0.0099 & $<0.0001$ \\
\hline
\end{tabular}


Table 3. Descriptive notes of the plumage and soft parts of C. t. thalassina and C. $t$. jefferyi.

\begin{tabular}{|c|c|c|c|c|}
\hline Trait & thalassina & jefferyi & $\begin{array}{l}\text { Interpretation of } \\
\text { difference (as per } \\
\text { Tobias et al. 2010) }\end{array}$ & Score \\
\hline Tertials & $\begin{array}{l}\text { more extensively } \\
\text { light green (white } \\
\text { in museum specimens); } \\
\text { base of outer webs } \\
\text { reddish brown, outermost } \\
\text { tertiary with the outer web } \\
\text { near tip also reddish brown, } \\
\text { in some cases with only two } \\
\text { pale spots at the tip (Kuroda } \\
\text { 1933; pers. obs.) }\end{array}$ & $\begin{array}{l}\text { Inner secondaries } \\
\text { greenish white, } \\
\text { except on outer web, } \\
\text { which is for the most } \\
\text { part claret-red, the } \\
\text { outermost one with a } \\
\text { oblique pale tip (Whitehead } \\
\text { 1893; pers. obs.) }\end{array}$ & $\begin{array}{l}\text { Considerable variation } \\
\text { in pattern in both } \\
\text { taxa is not gender- } \\
\text { specific but individual } \\
\text { or age-related. This } \\
\text { difference is 'medium', } \\
\text { as it involves a different } \\
\text { tone of a distinctly- } \\
\text { demarcated body part }\end{array}$ & 2 \\
\hline Rectrices & $\begin{array}{l}\text { uniform bluish green, with } \\
\text { diffusely pale tips only to } \\
\text { the outermost rectrices }\end{array}$ & $\begin{array}{l}\text { rectrices have white tips } \\
\text { and dark subterminal bars. }\end{array}$ & $\begin{array}{l}\text { 'major', as it involves a } \\
\text { different pattern } \\
\text { (barring versus no } \\
\text { barring) in a tract } \\
\text { of feathering }\end{array}$ & 3 \\
\hline Eyes & $\begin{array}{l}\text { red (Vorderman 1886a) to } \\
\text { bright coral red } \\
\text { (Kuroda 1933) }\end{array}$ & $\begin{array}{l}\text { white with a faint pink } \\
\text { tinge round the pupil } \\
\text { (Whitehead 1893) }\end{array}$ & $\begin{array}{l}\text { Note that - contra dos } \\
\text { Anjos (20o9) - orbital } \\
\text { ring in jefferyi is not } \\
\text { light blue but crimson } \\
\text { red as in thalassina } \\
\text { (see photos www.oriental } \\
\text { birdimages.org. Iris colour } \\
\text { difference is 'major' as it } \\
\text { involves a different } \\
\text { bare-parts coloration }\end{array}$ & 3 \\
\hline
\end{tabular}

an obviously finer bill in jefferyi (Fig. 3 b). This divergence in tail length and bill shape may indicate slight differences in ecological adaptations. Finally, there is no significant difference in total length between jefferyi and thalassina. Male and female measurements were always pooled in each taxon, since limited sexual differences were detected (data not shown).

Table 4. Interpretation of biometric differences according to criteria in Tobias et al. (2010); note that body ratios are not listed since they co-vary with their constituent parameters.

\begin{tabular}{|c|c|c|}
\hline $\begin{array}{l}\text { Biometric difference } \\
\text { between jefferyi and thalassina }\end{array}$ & $\begin{array}{l}\text { Effect size (Cohen's d) } \\
\text { and interpretation (as per } \\
\text { Tobias et al. 2010) }\end{array}$ & Score \\
\hline Tail longer in jefferyi & $\mathrm{d}=3.99$, i.e. 'medium' & 2 \\
\hline Tarsus longer in thalassina & $\mathrm{d}=2.14$, i.e. 'medium' & o \\
\hline Wing longer in thalassina & $\begin{array}{l}\mathrm{d}=1.64 \text {, i.e. 'minor' (score } 1) \\
\text { but cap on } \leq 2 \text { biometric traits }\end{array}$ & o \\
\hline Bill higher in thalassina & $\begin{array}{l}\mathrm{d}=3.47, \text { i.e. 'medium' (score } 2 \text { ), } \\
\text { but cap on } \leq 2 \text { biometric traits }\end{array}$ & 2 \\
\hline Bill longer in thalassina & $\begin{array}{l}\mathrm{d}=\text { o.89, i.e. 'minor' (score } 1 \text { ), } \\
\text { but co-varies with bill height }\end{array}$ & o \\
\hline Body longer in jefferyi & $\begin{array}{l}\mathrm{d}=1.38 \text {, i.e. 'minor', but co-varies } \\
\text { with tail length }\end{array}$ & o \\
\hline
\end{tabular}



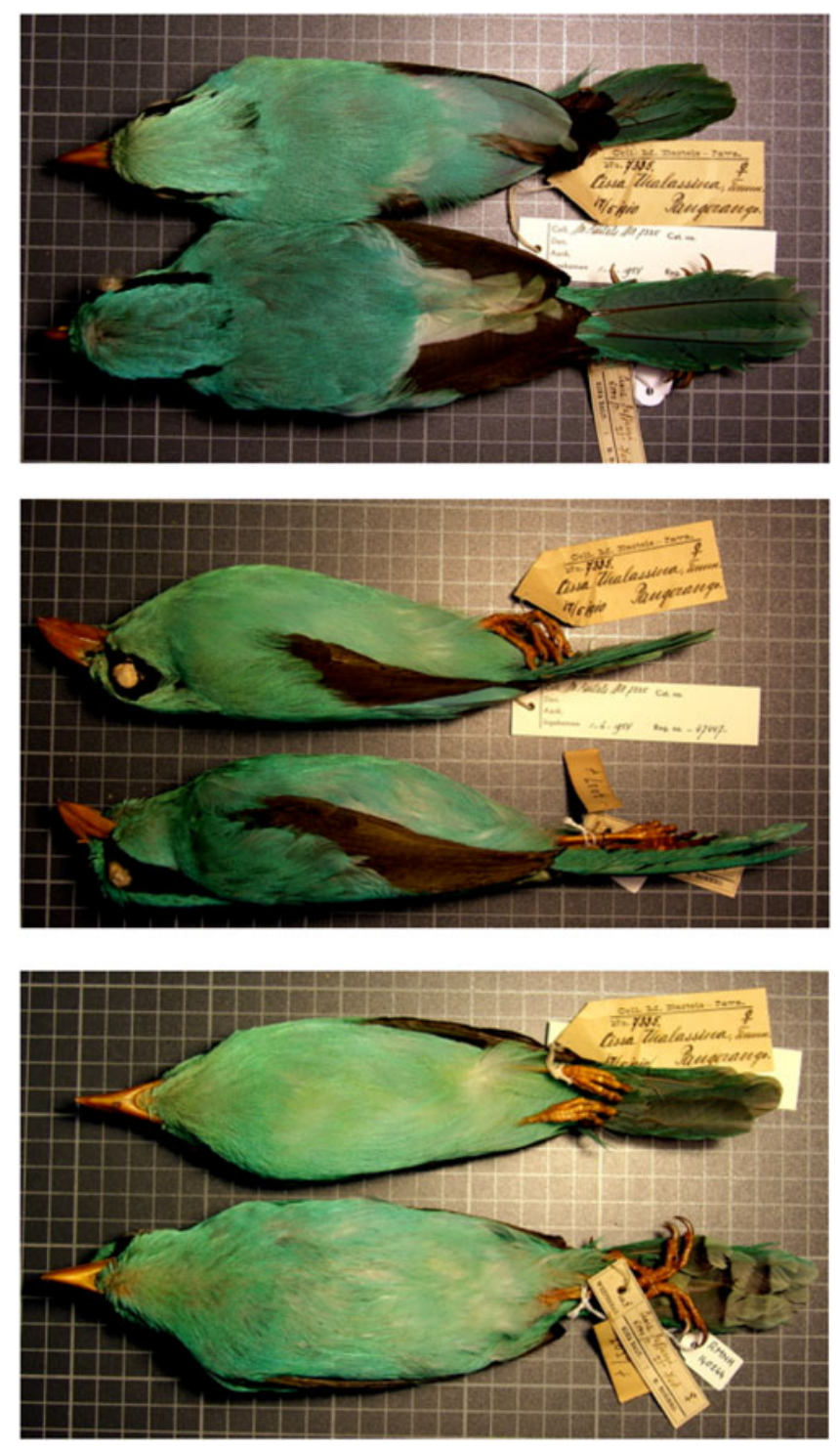

Figure 3. a-c. Specimens (in NCB Naturalis, Leiden) of Cissa t. thalassina (above) and C. t. jefferyi (below) showing the differences in tail length and tertial pattern (a, dorsal), bill shape and size (b, lateral), and pattern of under tail (c, ventral.) (Photos: S. v. B).

Weight of all taxa is about the same, 120-133 $\mathrm{g}$ (chinensis), $125 \mathrm{~g}$ (hypoleuca), $125 \mathrm{~g}$ (thalassina / jefferyi), although this dataset is far too small for statistical analysis.

\section{Plumage and soft parts}

Fig. 3 shows representative adult specimens of both Javan and Bornean Short-tailed Green Magpie. Table 3 provides descriptions of the body parts that are most strikingly different between these two taxa. 


\section{Phenotypic species delimitation test}

We carried out a novel species delimitation test introduced by Tobias et al. (2010) that interprets phenotypic taxon differences related to biometrics, coloration, bioacoustics, ecology and behaviour, and assigns scores from zero to four according to strict criteria on the level of differentiation in those traits. Based on a comparison with a large pool of pairs of known sister species, Tobias et al. (2010) consider the score of 7 a threshold for recognition as a biological species. Table 3 lists the differences in coloration between thalassina and jefferyi and indicates a total score of 8 for colour traits, which already surpasses Tobias et al.'s (2010) species threshold and indicates that the two taxa merit recognition as species based on coloration alone.

A fourth trait has been given by dos Anjos (2009) as subspecifically diagnostic, i.e. a yellow wash on crown and underparts of the Javan birds. As there is only a very slight difference in green between the two taxa, mainly on the head (see Figure 3) we did not consider it in our analysis. Moreover, Vorderman (1886) who described a freshly killed bird from Mt Salak, west Java, makes no mention of a yellow wash: ". . plumage bright pale blue-green, that has a pronounced green wash on head, belly and flanks."

Table 4 lists the interpretation of biometric differences according to the criteria set forth by Tobias et al. (2010) and indicates an additional score of 4 , which adds up to a score of 12 , well beyond the species threshold. Ecological or behavioural differences between the two taxa appear to be insignificant, although there is a difference in altitudinal range (see below), and the Javan birds seem to venture out of the forest (see below), resembling Cissa chinensis rather than the Bornean Short-tailed, that never leaves true forest (Whitehead 1893).

As far as vocal differentiation between jefferyi and thalassina is concerned, the extensive complexity of vocal characters and the abundance of motif types as well as the difficulty in classifying motif types into 'songs' and 'calls' make the application of Tobias et al.'s (2010) criteria to bioacoustic data in the genus Cissa challenging. In our vocal analysis of taxon differences (see above), we have dealt with these difficulties by showing that thalassina is vocally closer to $C$. chinensis than to jefferyi, and by focusing on a comparison of motif types, but it is not straightforward to adjust this type of analysis to the methodology put forth by Tobias et al. (2010). Therefore, we here abstain from applying their phenotypic test to vocal characters in jefferyi and thalassina, while noting that inclusion of the extensive vocal differences between homologous vocalisations detected by us (see above) would certainly further increase the test score. Since the test diagnostic is already at $12-$ and well beyond the species threshold at $7-$ after only biometric and colour characters are included, we deem the incorporation of vocal characters unnecessary for the purposes of this test.

\section{Discussion}

\section{Vocal differences}

Cissa magpies belong to the oscine songbirds, in which vocalisations are a learned rather than an inherent trait. In addition, they are great vocal imitators and are characterised by an astounding vocal repertoire. Consequently, they are a difficult subject for vocal analysis, since bioacoustic parameters must be compared amongst homologous vocalisations only. With the wide range of different motifs given by each Cissa taxon, the difficulty lies in the assignment of vocalisations to correct homologous motif classes. Using a range of 18 recordings from four taxa, but with a special emphasis on C. t. thalassina, C. t. jefferyi and C. hypoleuca, we have classified Cissa sounds into 12 motif types (A-L) - depicted in Fig. I - six of which (A-F) we believe to be shared amongst 2-3 Cissa taxa. We believe that our assignment of vocalisations into homologous motif types has been successful, because we have detected almost no discrepancies in the number of notes given per motif type amongst different taxa. Equally, when comparing each shared motif type (A-F) among different taxa in terms of motif durations and three different frequency parameters, we found substantial overlap in measurements between taxa (Table 1). No such 
overlap would be expected in categories that consist of non-homologous vocalisations inaccurately classified into the same motif types. Even so, vocal differentiation amongst taxa is expected to produce measurement differences in at least a number of parameters and motif classes, which conforms to our observation of limited overlap between taxa in some vocal parameters in motifs $\mathrm{A}, \mathrm{B}$ and $\mathrm{F}$.

C. t. jefferyi and C. t. thalassina were found to share only one motif type (D), which is probably ancestral because it is not exclusive to them, having been found also in C. hypoleuca (Fig. 2). In contrast, sharing of motif types was greatest between C. t. thalassina and C. hypoleuca (Fig. 2). Further vocal evidence that C. t. jefferyi and C. t. thalassina exhibit substantial vocal differences is the finding that C. t. jeffery $i$ was the only one of all four taxa that is characterised by a significant lack of harmonics in its vocal delivery. Harmonics create a particular vocal timbre that often sounds scratchy or non-melodious to the human ear, and they are regularly employed by C. t. thalassina as well as the two other Cissa species investigated. Therefore, C. t. jefferyi sounds considerably more melodious than the other taxa in its overall motif delivery. Last but not least, we found that the overall lowest frequency in motif delivery - regardless of motif type - is considerably lower-pitched in C. t. thalassina than in the other species, especially (and significantly so) in comparison to C. t. jefferyi.

Although the vocal complexity of Cissa vocalisations renders bioacoustic analysis challenging, it is clear that the vocal repertoire and a number of general vocal qualities of $C$. t. thalassina differ greatly from its supposed conspecific C. t. jefferyi, and that C. t. thalassina may in fact be vocally more similar to $C$. hypoleuca. This similarity between the Javan and the Indochinese taxa supports biogeographic findings in other bird species that Javan fauna may be more closely related to species from the subtropical monsoon forests north of the Sundaic rainforest zone (Medway and Wells 1976, Wells 1985, Holmes 1985). Whereas these are exclusively lowland species, there are examples of montane bird species that have also been separated sufficiently long for speciation and whose distributions show analogies with that of the magpie, i.e. Javan Tesia Tesia superciliaris, and Spotted Crocias Crocias albonotatus, all restricted to the western half of Java and with their closest relatives in mainland Asia, not on Sumatra or Borneo. Other west Javan endemics have allospecies on Sumatra (e.g. Javan Trogon Apalharpactes reinwardti and Javan Cochoa Cochoa azurea).

\section{Morphological differences}

Statistical analysis of biometric differences demonstrates that thalassina is a significantly shortertailed bird than jefferyi, even though its tarsus and wings are significantly longer. In addition, the two taxa exhibit an important divergence in bill morphology, with thalassina having a slightly longer and distinctly more massive bill than jefferyi. These biometric differences may reflect adaptations to slightly different life histories, but more research is needed to confirm this. We also document important differences in coloration, especially in brightly-coloured parts of the body (iris, wing panel, tail) that may serve a signalling function. In summary, our morphological data support our bioacoustic analysis in that jefferyi and thalassina should be afforded biological species rank.

\section{Phenotypic species delimitation test and taxonomic recommendation}

Even though our application of Tobias et al.'s (2010) species delimitation test did not include our bioacoustic dataset (see Results), and despite the fact that its inclusion would have further increased the test diagnostic, we arrived at a score of 12 , well beyond the species threshold of 7 . This high score confirms our conclusion that jefferyi and thalassina are well-differentiated taxa that deserve to be recognised at the biological species level. Perhaps most importantly, this conclusion is based on the independent documentation of profound differences in vocalisations, visual cues as well as structural parameters that may reflect adaptations to the environment. 


\section{Ecology}

\section{Distribution and habitat}

The elevational distribution of $C$. t. thalassina of $1,000-1,200 \mathrm{~m}$ as reported in the latest standard works (dos Anjos 2009) does not fully match our findings. Although occasionally encountered in lowland forest (Koningsberger 1915), the main distribution is in submontane and montane forests at 500-2,000 m (Sody 1956). Appendix $\mathrm{S}_{1}$ in the online Supplementary Materials lists all records of Cissa t. thalassina that we could find. Three specimens in RMNH and MZB without dates or exact localities (Bogor, Sukabumi and Priangan) have been omitted.

Bornean and Javan Green Magpies occupy largely overlapping altitudinal ranges, respectively $305-2,735$ and 500-2,000 $\mathrm{m}$. The former seems to occur higher up in the hills, possibly because of competitive exclusion with its congener $C$. chinensis in the lowlands, as nowhere do they seem to co-occur (Whitehead 1893). There is no obvious reason why the apparently more stenotopic Javan birds do not occur above 2,00o $\mathrm{m}$, where no competitors occur, and theoretically its larger size should actually be in its favour (James 1970). This anomaly may be partly explained by the massenerhebung effect of the 4,101 $\mathrm{m}$ high Mt Kinabalu, as compared to the smaller mountains in western Java, the highest of which is the 3,418 m Mt Slamet, but most are c.3,00o m or lower. Bartels (1931) described its habitat in and around a tea plantation on the south-western slopes of Mt Patuha, where during their raiding parties the magpies venture out far into the tea gardens; they prefer the forest fringes along the rivers.

\section{Food}

The old names Hunting Crow or Hunting Cissa (Madge and Burn 1994) very aptly describe its voracious nature. They are found in troops, or seasonally in pairs (Koningsberger 1915), not uncommonly accompanied by Rufous-fronted Laughingthrush Garrulax rufifrons (Koningsberger 1907), and often found near mixed bird parties (Delsman 1927).

Table 5 shows the items found in the stomach content of 34 specimens (Vorderman 1886, Bartels 1897-1931, Sody, in Becking 1989). Throughout the year invertebrates form the most important element. A variety of prey items has been found in stomachs: snails; crustaceans: crayfish Astacidae (Decapoda), pill bugs Armadilliidae (Isopoda); insects: cockroaches Blattidae (Dyctyoptera), grasshoppers (Orthoptera), 'may-beetles' Scarabaeidae, weevils Curculionidae, Chalcothea spp. Cetoniidae, horned beetles Cerambycidae, click beetles Elateridae (Coleoptera), cicadas (Homoptera), caterpillars (Lepidoptera), large ants Formicidae (Hymenoptera). Larger vertebrate prey (small birds, lizards, including their eggs, tree frogs, and snakes) constitutes a large part in first three months of the year only, largely coinciding with the breeding season.

\section{Breeding}

Although data are scarce and conclusions cannot be reliably drawn, it appears that breeding takes place during most of the year with a preponderance for the wettest months, i.e. October -April in

Table 5. Food items in stomach content of Cissa thalassina (from Vorderman 1886; M. Bartels 1897-1931). I: Jan-Mar, II: Apr-Jun; III: Jul-Sep; IV: Oct-Dec.

\begin{tabular}{lccrr}
\hline & I & II & III & IV \\
\hline$n$ samples & 10 & II & 2 & 12 \\
Invertebrates & 18 & 24 & 7 & 20 \\
Vertebrates & 13 & I & 1 & 5 \\
Fruits & 1 & 0 & O & 2 \\
\hline
\end{tabular}


west Java (Voous 1950): Jan (3), Feb (1), Mar (1), Apr (3), Sep (1), Dec (2) (after data from Bartels 1897-1931, Hoogerwerf 1949, 1950, Hellebrekers and Hoogerwerf 1967, J. H. Becking unpubl. data). Birds are freshly moulted at the end and beginning of the year (Bartels 1902).

Meyer (1884) reported a "...cup-shaped nest on the thin twigs of a large-leaved tree, consists of a base of stronger stalks or branches, then tendrils and thin twigs, intertwined with many dry leaves of bamboo, rice etc; inside lined with black thin roots; $80 \mathrm{~mm}$ high, 170-180 $\mathrm{mm}$ wide, inner cup $65 \mathrm{~mm}$ deep and $110 \mathrm{~mm}$ wide.". Bartels (1897-1931) "... found its nest twice on thin trees in a tree fork close to the trunk, of rather solid built, but not very large in relation to bird's size ...". Hoogerwerf (1950) : "...usually not high above the ground (3-6 m)...in not thick branches...base and outside consists of dry leaves, both from trees and rattan etc. Nest cup lined with plant parts looking like thin, dark rootlets, and petioles, stems, etc...". Becking (unpubl. data) reported a nest in a Tarenna incerta tree at $2.5 \mathrm{~m}$ above the ground in a Manglietia experimental plot, another in a small tree in undergrowth at $3 \mathrm{~m}$ above the ground in primary forest.

Clutch size is one egg $(n=1)$ or two $(n=7)$ (Hoogerwerf 1949, Hellebrekers and Hoogerwerf 1967). The egg is described as "oval, coarse-grained, smooth, and moderately glossy, with yellowish-white ground colour with few grey violet primary stains, and marked on the entire surface with uniformly distributed smaller reddish-yellow secondary stains; also this egg shows the close relationship with Cissa chinensis" (Kuschel 1895). Eggs of C. t. thalassina ( $n=17$; Hoogerwerf 1949, Hellebrekers and Hoogerwerf 1967, Becking unpubl. data) average $32.78 \mathrm{~mm}$ (31.1-34.3 mm) x $22.61 \mathrm{~mm}$ (range 22.0-23.30).

It has been frequently reported that incubating birds with young or eggs are very steady, "... leaving their nest only when the nest tree is climbed..." (Bartels 1897-1931; J.H. Becking unpubl. data); this certainly makes them vulnerable to bird trapping.

\section{Conservation}

\section{Bird trade}

According to Rutgers and Norris (1977), they do not appear often in collections, and in 1861 the taxon was first imported to London. The magpie is a moderately popular cage bird on Java, despite the quick loss of its bright green colour in captivity, but possibly compensated by its loud and clear calls, making it attractive for local bird fanciers. Numbers seen on local bird markets have always been small and during 1979-1986 they were rather erratically seen for sale on the bird markets in Bandung and Bogor (S. v. B pers. obs.), i.e. not always present and mostly in singles: (i) Many (25-125 birds, relatively expensive) in October-May 1978, Bandung (Iskandar 1980). (ii) A comprehensive survey of the Yogya bird market in February 1979 counted a single bird (van Balen et al. in prep.). (iii) Regular visits to the bird market in Bogor in 1979-81 yielded only few records; in Bandung 1981-86, few each time. (iv) None were seen among 150,000 birds on a Jakarta bird market in December 1987 (Basuni and Setiyani 1989). (v) A study into the bird trade in Indonesia in 1992-93 found C. t. thalassina in 25 of 39 surveys of mainly Javan bird markets; it was also reported that 320 were authorised for export between August-December 1992 (Nash 1993). (vi) Often seen on bird markets in the past, but now very rarely, and currently prices have been sky-rocketing to Rp 1,200,000 per bird (R. Sözer in litt. 2011), which is more than the local minimum wage per month (Wordpress 2011).

The relative popularity of green magpies in general is indicated by the moderately large numbers of Cissa chinensis found during a bird market survey in 1997-2001 in Medan: between 121 and 264 (Shepherd et al. 2004) meaning an average of 10-20 birds each survey, suggesting a certain popularity of green magpies, and in February 1995, three Cissa chinensis were seen offered for sale in the west Javan town of Purwakarta (S. v. B. unpubl. data).

For Mt Halimun, Riffel (1991) reports that many are caught, as also communicated in April 1995 by Suandi (Carucub village) to S. v. B. In the Lumping (Dieng Mts) in the mid 199os bird catchers were mostly people of the village, but also a trapper from western Java who specialised in 
green magpies was reportedly active in the area. These trappers were only active in October and November when the main bait to catch forest birds, winged termites (laron), were available in abundance.

\section{Habitat fragmentation}

Most forest up to $1,000 \mathrm{~m}$ and locally up to $1,500 \mathrm{~m}$ has disappeared on Java (van Balen 1999), thus largely affecting the range of the magpie. No magpies are known from montane forest patches that are small and have been isolated since prehistoric times, such as Mts Karang, Muriah, Ciremai, and Ungaran, indicating that the species is sedentary. This might also explain why this species never occurred in the eastern half of Java.

Although classified by Wells (1985) as dependent on montane habitat, they might be better regarded as one of his 'lowland slope specialists'. With the near-total deforestation of Java's lowlands and ongoing encroachment beyond $1,000 \mathrm{~m}$ and even $1,500 \mathrm{~m}$, this taxon faces a real risk of local or even overall extirpation, as it is being 'locked up' in increasingly narrow forest bands (van Balen 1988). Interestingly, the Bornean jefferyi has a considerably wider range, from 305 to $2,735 \mathrm{~m}$, though rarely below 1,400 m, where it overlaps at lower altitudes, 305-1,530 m, with the Common Green Magpie Cissa chinensis minor, but both species appear to be mutually exclusive on Mt Kinabalu (Whitehead 1893) above and below 1,000 m.

\section{Status assessment}

The taxon jefferyi appears to be secure in its remote haunts in the interior of Borneo, especially in well-protected reserves such as Kinabalu National Park. The following discussion on conservation therefore solely refers to the Javan Green Magpie.

Three parameters for IUCN threatened category thresholds (Collar et al. 1994, IUCN 2001, BirdLife International 2001) were assessed for the Javan Green Magpie: (i) population decline, (ii) population size, and (iii) small range size. (i) The observation that few or no green magpies have been seen in the past 25 years, even in areas where they used to be seen quite regularly (Mts Halimun-Salak, and Mts Gede-Pangrango), and the nearly total disappearance from local bird markets where they were seen more or less frequently in the past, suggests a serious decline in numbers, which certainly exceeds $80 \%$ in the past 10 years. As shown, they have probably been completely extirpated from many of the sites where they were last recorded in the $2 \mathrm{O}^{\text {th }}$ century. (ii) Populations at the 1-4 sites where there is a potential chance of their present survival must certainly be very small, probably not exceeding one or two dozen individuals. The global wild population size therefore probably does not exceed 100 and is quite possibly below 50 individuals. Excessive capture for the bird trade and habitat destruction are the ultimate causes of the extreme rarity of the magpies. The survival of small remaining populations is now jeopardised by the fact that catchers specialise in one or more species. This inevitably means that local populations are specifically targeted, with an increased risk that the last remaining birds in the wild are extirpated sooner or later. (iii) Their extent of occurrence (global range) is probably c.2,410 $\mathrm{km}^{2}$. The ongoing deterioration of suitable habitat has undoubtedly caused the shrinking of its range from nine to four, or fewer, localities.

The area of occupancy (actual area inhabited) of $1,680 \mathrm{~km}^{2}$ is calculated from the total area of localities where the magpie has been seen since 2000 (Table 6). This figure is more than likely too optimistic, given the lack of more recent records, and the fact that only part of these areas consists of suitable habitat. Moreover, only four localities are reserves that are moderately or hardly fragmented, enjoy sufficient protection against hunting and habitat destruction, and where observations date from this century.

Based on the above observations, we note that the Javan Green Magpie fulfils four criteria for 'Critically Endangered' status: 
Table 6. Forest blocks in West and Central Java with recent and historical records of Cissa thalassina. Abbreviations: NP, National Park; NR, Nature Reserve; PF, Protection Forest. Fragmentation score: 1 , one large compact area; 2, several medium-sized, interconnected forest areas; 3, several small to intermediate areas, with or without adjacent smaller areas.

\begin{tabular}{|c|c|c|c|c|c|}
\hline & Status & Area $\left(\mathrm{km}^{2}\right)$ & Alt. range ( $\mathrm{m}$ asl) & $\begin{array}{l}\text { Fragmen- } \\
\text { tation }\end{array}$ & $\begin{array}{l}\text { Most recent } \\
\text { record }\end{array}$ \\
\hline Mts Halimun-Salak & NP & 500 & $400-2,210$ & 1 & 2005 \\
\hline Jampang Kulon & - & 100 & $0-400$ & 3 & 1906 \\
\hline $\begin{array}{l}\text { Mts Gede-Pangrango / } \\
\text { Megamendung }\end{array}$ & NP & 200 & $500-3,019$ & 2 & 2002 \\
\hline North Parahyangan & $\mathrm{PF} / \mathrm{NR}$ & 100 & $900-2,018$ & 3 & 1941 \\
\hline South Parahyangan & PF/NR & 900 & $300-2,622$ & 2 & 2006 \\
\hline Pembarisan Mts & $\mathrm{PF}$ & 130 & $300-1,351$ & 2 & 1994 \\
\hline Mt Slamat & PF & 150 & $700-3,418$ & 1 & 1917 \\
\hline Dieng Mts & $\mathrm{PF}$ & 250 & $250-2,565$ & 2 & 1995 \\
\hline Mt Merapi & NP & 80 & $1,000-3,142$ & 2 & 2005 \\
\hline
\end{tabular}

- Criterion Aza: a projected decline of $\geq 80 \%$ over 10 years based on observation; - Criterion $C_{1}$ : a global population size of $\leq 250$ mature individuals that are declining at $\geq 25 \%$;

- Criterion C2a: a global population size of $\leq 250$ mature individuals that are severely fragmented, with $\leq 50$ individuals per sub-population;

- Criterion D: a global population size that may well be $\leq 50$ mature individuals.

\section{Measures taken}

Cissa thalassina has been observed in only four localities in the last 1o years. These are Mts Halimun-Salak, Mts Gede-Pangrango, Gunung Simpang and Mt Merapi. The first and second sites are more or less well-established national parks, where despite the huge importance of the endemic biodiversity they support, much encroachment (agriculture, logging, mining, birdcatching) occurs along their borders. Gunung Simpang is a strict nature reserve, whereas Mt Merapi was given national park status a few years ago, but its efficacy is debatable, as there is much resistance from local communities, and recent volcanic eruptions have destroyed much of the natural forest.

\section{Measures proposed}

(i) The Javan Green Magpie qualifies for immediate protection because of its precarious current situation. Any official protection measures however have to be taken with the greatest care, as drawing too much attention could easily boost its market price as a cage bird, as has happened previously with endangered species (Nijman et al. 2009). (ii) Law enforcement and awareness programmes in the last refuges of the magpie, Mts Halimun-Salak, Mts Gede-Pangrango, Gunung Simpang and Mt Merapi protected areas should be intensified, and focused on proper protection of the forest at the lower to mid-elevations. (iii) Any Javan Green Magpies that are encountered in captivity should be immediately rescued for either a captive breeding programme or release into the wild. Only birds that are unsuitable for release, for instance by having been in captivity too long (as indicated by fading of the green plumage into blue) should be considered for a captive breeding programme. Currently a feasibility study for a breeding programme in the Cikananga wildlife rescue center at Sukabumi, West Java, is supported by Chester Zoo (UK) (R. Sözer in litt. 2011). Release attempts should be undertaken into their areas of origin, or in areas where re-stocking is preferable, but only provided that these actions are backed by increased law enforcement and awareness programmes, as otherwise the released individuals may well be 
illegally captured again shortly after release. (iv) Surveys should be undertaken in remaining forest patches with extensive suitable habitat, that have been undersurveyed but where the presence of green magpies is expected, e.g. Gunung Sawal (5,400 ha, 60o-1,764 m) and Gunung Ciremai $(12,000$ ha, 1,000-3,078 m). Areas where magpies were historically known to occur should also be surveyed.

\section{Conclusion}

The significant differences in biometrics and coloration as well as strong vocal differences warrant an upgrading of both the Bornean and Javan subspecies of Short-tailed Green Magpie to species status. We propose the English names Bornean Green Magpie Cissa jefferyi and Javan Green Magpie Cissa thalassina.

Only four or fewer localities in western Java appear to harbour Javan Green Magpie. Their numbers must have seriously declined in the past 25 years; and its present extent of occurrence is little more than $2,100 \mathrm{~km}^{2}$, whereas in its area of occupancy only a fraction of the original population may remain. Pending specialised surveys in potential areas, we propose the status of globally 'Critically Endangered' for the Javan Green Magpie, based on IUCN criteria.

\section{Supplementary Material}

The supplementary materials for this article can be found at journals.cambridge.org/bci

\section{Acknowledgements}

Thanks are due to Vincent Nijman, Pupung Nurwatha, Adhy Maruly, Prayudhi, Indra Ferdinand, Nick Brickle, Pete Wood, David K. Bishop, Frank Lambert and Resit Sözer for sharing their records of Green Magpie on Java. Thanks also go to Steven van der Mije (NCB Naturalis, Leiden), Mohammad Irham (Museum Zoologicum Bogoriense at Bogor, Indonesia) and Mark Adams (British Natural History Museum at Tring, UK) for access to their bird collections. Dave Farrow, Craig Robson, David Edwards, Brian Cox, Arnold Meijer, Nick Athanas, Rob Hutchinson, Mike Nelson and Frank Lambert are thanked for providing their sound recordings through the online database http://www.xeno-canto.org.

\section{References}

Andrew, P. (1985) An annotated checklist of the birds of the Cibodas-Gunung Gede Nature Reserve. Kukila 2: 10-28.

dos Anjos, L. (2009) Family Corvidae (Crows). Pp. 494-640 in J. del Hoyo, A. Elliott and D. A. Christie, eds. Handbook of the birds of the world. Volume 14. Bushshrikes to Old World sparrows. Barcelona: Lynx Edicions.

van Balen, J. H. (1918) De dierenwereld van Insulinde. II. De vogels. Zutphen, The Netherlands: Thieme.

van Balen, S. (1984) Comparison of bird counts and bird observations in the neighbourhood of Bogor (Indonesia). Student Report. Utrecht: State University of Utrecht.

van Balen, S. (1988) Forest fragmentation and the survival of forest birds in Indonesia: a preliminary report. Pp. 115-165 in Proc. Seminar Nachkontakt DAAD, Bogor 9-11 December 1987.

van Balen, S. (1999) Birds on fragmented islands: persistence in the forests of Java and Bali. PhD dissertation. Wageningen: Wageningen University.

Bartels, M. E. G. (1902) Zur Ornis Java. Natuurk. Tijdschr. Ned-Indië 61: 129-172.

Bartels, M. (1906) Systematische Übersicht meiner Java-Vögel. J. Orn. 54: 383-407, 497-519.

Bartels, E. (1897-1931) Vogels van Kole Beres. Natuurk. Tijdschr. Ned-Indië 91: 308-348. 
Basuni, S. and Setiyani, G. (1989). [Bird trading at the Pasar Pramuka, Jakarta and the bird catching techniques] Media Konservasi 2 (2): 9-18. (In Indonesian, with English summary).

Becking, J. H. (1989) Henry Jacob Victor Sody (1892-1959). His life and work. Leiden, The Netherlands: Brill.

BirdLife International (2001) Threatened birds of Asia. The BirdLife International Red Data Book. Cambridge, UK: BirdLife International.

Collar, N. J., Crosby, M. J. and Stattersfield, A. J. (1994) Birds to watch 2. The world list of threatened birds. Cambridge, UK: BirdLife International. (BirdLife Conservation Series 4).

Chasen, F. N. (1935) A handlist of Malaysian birds. Bull. Raffles Mus. 11: 1-389.

Delacour, J. (1929) Révision du genre Cissa. L'Oiseau et R.F.O. 10: 1-12.

Delsman, H. C. (1927) Vogelleven in het oerbosch II. Trop. Nat. 16: 82-89.

Dickinson, E. C., Eck, S. and Martens, J. (2004) Systematic notes on Asian birds. 44. A preliminary review of the Corvidae. Zool. Verh. Leiden 350: 85-109.

Forbes, H. O. (1885) A naturalist's wanderings in the Eastern Archipelago. London: Sampson Low, Marston, Searle \& Rivington.

Goodwin, D. (1976) Crows of the world. London, UK: British Museum (Natural History).

Goodwin, D. (1986) Crows of the world. $2^{\text {nd }}$ edition. London, UK: British Museum (Natural History).

Hellebrekers, W. P. J. and Hoogerwerf, A. (1967) A further contribution to our oological knowledge of the island of Java (Indonesia). Zool. Verh. Leiden 88: 1164.

Holmes, D. A. (1985) Ornithological reflections: the Thai connection. Voice of Nature 28: 13-15.

Hoogerwerf, A. (1948) Contribution to the knowledge of the distribution of birds on the island of Java. Treubia 19: 83-137.

Hoogerwerf, A. (1949) Bijdrage tot de oölogie van Java. Limosa 22: 1-279.

Hoogerwerf, A. (1950) The avifauna van Tjibodas en omgeving, inclusief het natuur- monument Tjibodas-Gn. Gede (West-Java). Limosa 23: 1-156.

Howard, R. and Moore, A. (1980) A complete checklist of the birds of the world. London, UK: Macmillan.

Iskandar, J. (1980) [Study of birds in several village areas in the Citarum catchment area]. Student Report. Bandung: Padjadjaran University. (In Indonesian).

IUCN (2001) IUCN Red List categories and criteria version 3.1. URL: http://www.iucn redlist.org/technical-documents/categoriesand-criteria/2001-categories-criteria

James, F. C. (1970) Geographic size variation in birds and its relationship to climate. Ecology 51: 365-390.

Koningsberger, J. C. (1907) Zoologische wandelingen te Tjibodas. II. Boschvogels. Teysmannia 18: 67-76.

Koningsberger, J. C. (1915). Java, zoölogisch en biologisch. Buitenzorg, The Netherlands: Department Landbouw, Nijverheid \& Handel. Kuroda, N. (1933) Birds of the island of Java 1. Passerines. Tokyo: published by the author.

Kuschel, M. (1895) Zur Oologie Javas. Orn. Monatsber. 3: 153-156.

Madge, S. and Burn, H. (1994) Crows and jays. London, UK: Helm.

Medway, Lord and Wells, D. R. (1976) The birds of the Malay Peninsula. Volume 5 Conclusion, and survey of every species. London and Kuala Lumpur: Witherby \& Penerbit Universiti Malaya.

Nash, S. V. (1993) Sold for a song. The trade in Southeast Asian non-CITES birds. Traffic Southeast Asia.

Nicholson, F. (1882) Supplementary notes to the list of birds collected by Mr. H.O. Forbes in the island of Java. Ibis 24: 66-71.

Nijman, V., Shepherd, C. R. and van Balen, S. (2009) Declaration of the Javan Hawk-eagle as Indonesia's National Rare Animal impedes conservation of the species. Oryx 43: $1-7$.

van Oort, E. D. (1910) List of a collection of birds from western Java and from Krakatau. Notes Leyden Mus. 32: 105-166.

Peters, J. L. (1962) Check-list of birds of the world. Vol. 15. Cambridge, MA: Harvard Museum of Comparative Zoology. 
Riffel, M. (1991) Gunung Halimun - ein positives Naturschutzbeispiel. Mitt. Zool. Gesellschaft für Arten- und Populationsschutz e.V 7 (2): 1-2.

Robinson, H. C. and Kloss, C. B. (1924) A nominal list of the birds collected on Java. Treubia 5: 267-298.

Rutgers, A. and Norris, K. A. (1977) Encyclopaedia of aviculture. Vol. 3. Poole, Dorset, UK: Blandford Press.

Scharringa, J. (2005) Birds of tropical Asia 3. Enschede, The Netherlands: Bird Songs International.

Shepherd, C. R, Sukumaran, J. and Wich, S. A. (2004). Open season: an analysis of the pet trade in Medan, Sumatra 1997-2001. Traffic Southeast Asia.

Sibley, C. G. and Monroe, B. L. (1990). Distribution and taxonomy of birds of the world. New Haven, CT and London, UK: Yale University Press.

Sodhi, N. S., Soh, M. C. K., Prawiradilaga, D. M., Darjono and Brook, B. W. (2005) Persistence of lowland rainforest birds in a recently logged area in central Java. Bird Conserv. Internatn. 15: 173-191.

Sody, H. J. V. (1956) De Javaanse bosvogels (Javanese forest birds). Indonesian J. Nat. Sci. 112: 153-170.

Sözer, R. and Nijman, V. (1995) Behavioural ecology, distribution and conservation of the Javan Hawk-eagle Spizaetus bartelsi Stresemann, 1924. Amsterdam, The Netherlands: Zoologisch Museum, Universiteit van Amsterdam. (Verslagen en Technische Gegevens 62).

Stresemann, E. (1930) Eine Vogelsammlung vom Vulkan Papandajan (West-Java). Treubia 12: 425-430.
Tobias, J. A., Seddon, N., Spottiswoode, C. N., Pilgrim, J. D., Fishpool, L. D. C. and Collar, N. J. (2010) Quantitative criteria for species delimitation. Ibis 152: 724-746.

de Visard de Bocarmé, J. (1829) Quelques observations faites à Java par le comte J. de Visard de Bocarmé sur les moers et habitudes d'oiseaux déjà projurés ou décrits dans divers ouvrages. Manuscript in NCB Naturalis Leiden, The Netherlands.

Vorderman, A. G. (1886) Bijdrage tot de kennis der avifauna van den berg Salak. Natuurk. Tijdschr. Ned-Indië 46: 304-414.

Vorderman, A. G. (1887) Bijdrage tot de kennis van de avifauna der Preanger Regentschappen langs de Wijnkoopersbaai (West-Java). Natuurk. Tijdschr. Ned-Indie 46: 65-90.

Walters, M. (1980) The complete birds of the world. London, UK: David and Charles.

Wells, D. R. (1985) The forest avifauna of Western Malesia. Pp. 213-232 in A. W. Diamond and T. E. Lovejoy, eds. Conservation of tropical forest birds. Cambridge UK: International Council for Bird Preservation. (ICBP Technical Publication 4).

Whitehead, J. (1893) Exploration of Mount Kina Balu, North Borneo. London, UK: Gurney \& Jackson.

Wind, J. and Soesilo, B. K. (1978) Proposed Halimun Nature Reserve management plan 1979-1982. Bogor, Indonesia: FAO.

Wolters, H. E. (1977) Die Vogelarten der Erde. Hamburg and Berlin, Germany: Paul Parey.

Wordpress (2011). [Information on regional minimum wages, 2010, 2011]. URL: http:// allows.wordpress.com/2009/o1/12/informasiupah-minimum-regional-umr. Accessed on 20 July 2011. (In Indonesian).

\section{S. (BAS) VAN BALEN*}

Basilornis Consults, Roompotstraat 44, 6826 EP, Arnhem, The Netherlands.

JAMES A. EATON

17 Keats Avenue, Littleover, Derby, DE23 4EE, UK. 
FRANK E. RHEINDT

Harvard University, Center for Organismic and Evolutionary Biology, 26 Oxford Street, Cambridge MA 02138 , USA.

*Author for correspondence; e-mail: bvanbalen001@hotmail.com

Received 17 February 2011; revision accepted 29 July 2011;

Published online 16 December 2011 